\title{
Uji Ketahanan beberapa Varietas Unggul Jagung terhadap Penyakit Gibberella dan Diplodia
}

\author{
Soenartiningsih \\ Balai Penelitian Tanaman Serealia, Maros \\ Email: Soenartiningsih@yahoo.com
}

\begin{abstract}
Gibberella and Diplodia ear rot is a disease that can damage the corn cobs and corn kernels resulting in lower quality and quantity of seed. The objective of the research are to find the varieties of corn which are resistant the ear rot disease Gibberella and Diplodia. This study was conducted in Limang Karo regency, North Sumatera, a randomized block design with three replications, each treatment comprised 4 rows and each row contained 25 plants with a spacing of $75 \times 20 \mathrm{~cm}$. The results showed 25 Hybrid maize tested against Gibberella ear rot there are 7 Hybrid corn hybrids that are resistant to ear rot Kenia-2, NK33, Bima 3, Bima 10 Bima 12 Q, NEI-9008 and X8B649 (check resistance) and moderately resistance there are 9 hybrid that Kenia-3, DK979, NK22, P12, Gumarang, Srikandi putih, Lamuru and Sukmaraga and 9 hybrid to ear rot disease were reacted susceptible and highly susceptible. Whereas from 25 Hybrid maize tested against Diplodia ear rot there are 6 Hybrid corn hybrids resistant to ear rot disease is Kenia - 2, NK33, Bima 3, Bima 12 Q, NEI-9008 and X8B649 (check resistance) while that is moderately resistancet there are 11 hybrid that is Kenia-3, DK979, NK22, P29, Bisi 2, P12, Bima 10, Gumarang, Srikandi putih, Lamuru and Sukmaraga, while 8 hybrid others were reacted susceptible and highly susceptible.
\end{abstract}

Key word : ear rot disease, Gibberella and Diplodia, varieties of corn

\begin{abstract}
Abstrak
Penyakit busuk tongkol Gibberella dan Diplodia adalah salah satu penyakit pada jagung yang dapat merusak tongkol dan biji jagung sehingga menurunkan kwalitas dan kwantitas biji. Tujuan penelitian ini yaitu menguji 25 varietas/galur jagung terhadap penyakit busuk tongkol Gibberella dan Diplodia. Penelitian ini dilaksanakan di Limang kabupaten karo Sumatera utara menggunakan rancangan acak kelompok dengan tiga ulangan, setiap perlakuan terdiri 4 baris dan setiap baris terdapat 25 tanaman dengan jarak tanam $75 \times 20 \mathrm{Cm}$. Hasil penelitian menunjukkan 25 Hybrid jagung yang diuji terhadap penyakit busuk tongkol Gibberella ada 7 Hybrid jagung hibrida yang tahan terhadap penyakit busuk tongkol Kenia-2, NK33, Bima 3, Bima 10, Bima 12 Q, NEI-9008 dan X8B649 (cek tahan) sedangkan yang bersifat agak tahan ada 9 hybrid yaitu Kenia-3, DK979, NK22, P12, Gumarang, Srikandi Putih, Lamuru dan Sukmaraga sedangkan 9 hybrid yang lain bersifat rentan dan sangat rentan. 25 Hybrid jagung yang diuji terhadap penyakit busuk tongkol Diplodia ada 6 Hybrid jagung hibrida yang tahan terhadap penyakit busuk tongkol yaitu Kenia-2, NK33, Bima 3, Bima 12 Q, NEI-9008 dan X8B649 (cek tahan) sedangkan yang bersifat agak tahan ada 11 hybrid yaitu Kenia-3, DK979, NK22, P29, Bisi 2, P12, Bima 10, Gumarang, Srikandi Putih, Lamuru dan Sukmaraga sedangkan 8 hybrid yang lain bersifat rentan dan sangat rentan.
\end{abstract}

Kata kunci: penyakit busuk tongkol, Gibberella and Diplodia, varietas jagung

\section{Pendahuluan}

Penyakit busuk tongkol Gibberella disebabkan cendawan patogen Gibberella zeae atau Fusarium graminearum sedangkan busuk tongkol Diplodia disebabkan oleh Stenocarpella maydis kedua penyakit ini banyak menyerang pertanaman jagung di sentra produksi jagung terutama pada musim hujan atau pada daerah yang mempunyai kelembaban tinggi (CIMMYT, 2004). Ada beberapa laporan Sumatera utara merupakan daerah endemi penyakit busuk tongkol, penyakit ini sangat berpengaruh terhadap penurunan kwalitas dan kwantitas jagung selain itu metabolisme sekunder dari kedua penyakit ini juga dapat mengeluarkan toksin yaitu diplodia toksin dan deoxynivalenol. Selain bagian tongkol dan biji cendawan ini dapat menginfeksi pada batang, pelepah daun dan dapat menyebabkan kerusakan tanaman secara luas sampai terjadi 
kematian dini pada tanaman, kerusakan pada biji karena adanya gangguan translokasi air dan nutrisi saat pengisian bijibijian (Mitter et al., 2006).

Kehilangan hasil karena penyakit busuk tongkol tergantung pada sejumlah faktor termasuk ketahanan varietasnya, kondisi iklim kerapatan tanaman, dan budidaya tanaman yang kurang optimal.

Berbagai cara pengendalian telah dilakukan terutama melalui penggunaan bahan kimia atau fungisida. Namun penggunaan senyawa kimia membutuhkan biaya yang relative mahal dan berpengaruh negative terhadap lingkungan. Kogan (1974) menyatakan bahwa penggunaan varietas tahan untuk pengendalian organisme pengganggu memiliki beberapa keuntungan antara lain mudah, murah dan bersifat spesifik terhadap organisme tertentu dan tidak mencemari lingkungan.

\section{Bahan dan Metode}

Sebelum dilakukan pengujian resistensi ketahanan terhadap penyakit busuk tongkol, maka dilakukan survey terlebih dahulu pada daerah sentra produksi jagung mengenai perkembangan penyakit Gibberella dan Diplodia yang terjadi di Sumatera utara. Setelah dilakukan survey pada daerah-daerah yang mempunyai intensitas serangan penyakit Gibberella dan Diplodia yang tinggi, baru dilakukan penelitian untuk menguji resistensi varietas. Penelitian uji resistensi dilaksanakan di Limang Kabupaten karo Sumatera Utara, penelitian dilaksanakan pada bulan Agustus- Desember 2014.

Tabel 1. Skoring tingkat serangan tongkol dan kategori ketahanan varietas

\begin{tabular}{|c|c|l|}
\hline No & Persentase serangan & \multicolumn{1}{|c|}{ Kategori } \\
\hline 1 & $0-10$ & Sangat Tahan (ST) \\
2 & $>10-20$ & Tahan (T) \\
3 & $>20-40$ & Agak Tahan (AT) \\
4 & $>40-60$ & Rentan (R) \\
5 & $>60-100$ & Sangat Rentan (SR) \\
\hline
\end{tabular}

\section{Koleksi Patogen dari lapang}

Tongkol jagung yang terserang penyakit diambil dan dimasukkan dalam kantong plastik dan dibawa ke laboratorium Hama dan Penyakit Balai Penelitian Tanaman Serealia di Maros untuk diisolasi dan diidentifikasi patogen penyebabnya.

\section{Isolasi Patogen}

Biji jagung yang terinfeksi dipipil kemudian biji tersebut dicelupkan beberapa detik pada larutan alkohol $70 \%$ untuk sterilisasi permukaan biji dimasukkan kedalam aquades steril pada cawan petri selama 10 menit supaya alkohol dipermukaan biji larut dalam aquades. Setelah itu biji diambil dengan pinset steril dan ditempatkan pada kertas saring steril di cawan petri sekitar $2-3$ jam sehingga aquades yang ada dipermukaan biji terserap semua oleh kertas saring tersebut. Selanjutnya biji tersebut ditanam atau ditaruh pada permukaan media PDA (Potato dextrose agar) steril dalam cawan petri dan diinkubasikan pada inkubator selama 7 hari. Cendawan yang tumbuh di cawan petri diamati setiap hari, pada saat pertumbuhan hifa sudah mencapai $2-3 \mathrm{~cm}$, diambil pinggiran koloni dengan scalpel dan dipindahkan pada media PDA steril yang lain untuk mendapatkan biakan murni. Biakan murni dibiarkan tumbuh beberapa hari sampai koloninya memenuhi permukaan cawan petri. Pada umur biakan 7 hari, sporanya diamati dengan mikroskop dan diidentifikasi.

\section{Hasil dan Pembahasan}

Tongkol yang terserang penyakit busuk tongkol dilakukan identifikasi di laboratorium cendawan yang banyak menginfeksi tongkol jagung di beberapa daerah kabupaten karo Sumatera Utara adalah Gibberella dan Diplodia sedangkan yang mempunyai intensitas serangan yang tinggi adalah daerah Limang Kabupaten karo Sumatera Utara sehingga untuk pengujian resistensi penyakit busuk tongkol dilakukan di Limang Kabupaten Tanah karo Sumatera Utara. 


\section{Hasil identifikasi di Laboratorium Gibberella}

Gejala penyakit ini adanya miselium yang berwarna putih kemudian berubah menjadi kemerah-merahan sampai keunguunguan pada bagian tongkol atau pada biji. Cendawan ini dapat bertahan hidup lama dalam bentuk perithecia dan ascospores dan berkembang kembali jika lingkungannya sesuai. Ascospores disebarkan oleh angin atau percikan air hujan ke tanaman jagung yang sehat. Pengamatan secara mikroskopis konidia dari Gibberella zeae bersifat hialin, sedikit melengkung, meruncing di kedua ujungnya, terdiri dari 5 sampai 6 septate. Condia ukuran $4-6 \times 10-$ $30 \mu \mathrm{m}$. (Beyer, 2005).

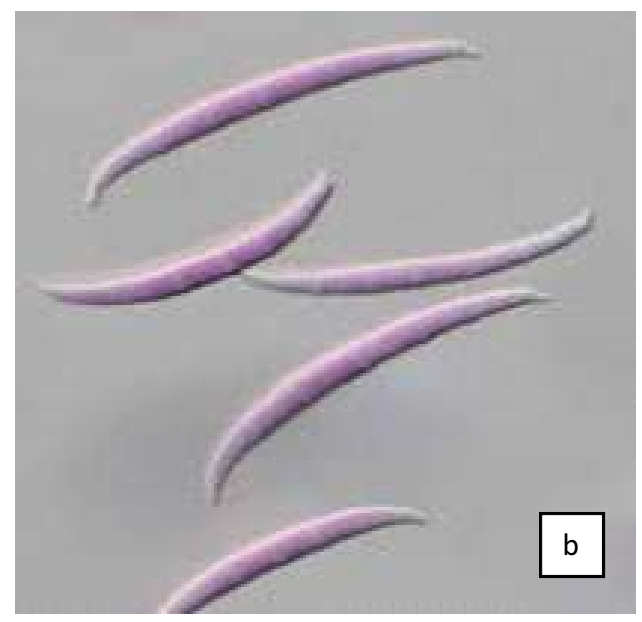

Gambar 1. Tongkol jagung yang terinfeksi Gibberella (a) dan Konidia Gibberella (b)

\section{Diplodia}

Infeksi awal yang terjadi pada biji belum terlihat hingga seluruh tongkol dan kelobot terserang. Adanya infeksi cendawan ini ditandai dengan adanya miselium berwarna putih hingga cokelat kelabu. Pembusukan biasanya berkembang dari pangkal ke ujung tongkol, selain pada bagian tongkol cendawan ini juga dapat menginfeksi pada bagian pelepah daun meluas ke buku dan pangkal ruas batang, busuk batang dimulai dari luka pada bagian pelepah (tempat keluarnya akar adventif). Deskripsi: Serangan penyakit ini menyebabkan adanya infeksi kompleks, yaitu busuk tongkol, busuk daun, dan penyakit pada persemaian (Charles, 2009). Pengamatan secara mikroskopis: cendawan ini bentuk konidia agak oval terdiri dari dua septa, berwarna coklat tua hingga kehitaman, dan berdiameter 50-100 $\mu \mathrm{m}$. Dindingnya dikelilingi oleh ostiol yang bulat dan menonjol, berwarna gelap dengan diameter $40 \mu \mathrm{m}$. Patogen mempertahankan diri di dalam biji dan hidup sebagai saprofit. Infeksi dimulai pada dasar tongkol, berkembang ke bonggol, kemudian merambat ke permukaan biji dan menutupi kelobot. Tongkol menjadi busuk dan kelobotnya saling menempel erat pada tongkol. Gejala busuk tongkol Diplodia adalah kelobot yang terinfeksi pada umumnya berwarna coklat. Infeksi pada kelobot setelah dua minggu keluar rambut jagung menyebabkan biji berubah menjadi coklat, kisut dan busuk (Akinsanmi et al., 2004) 

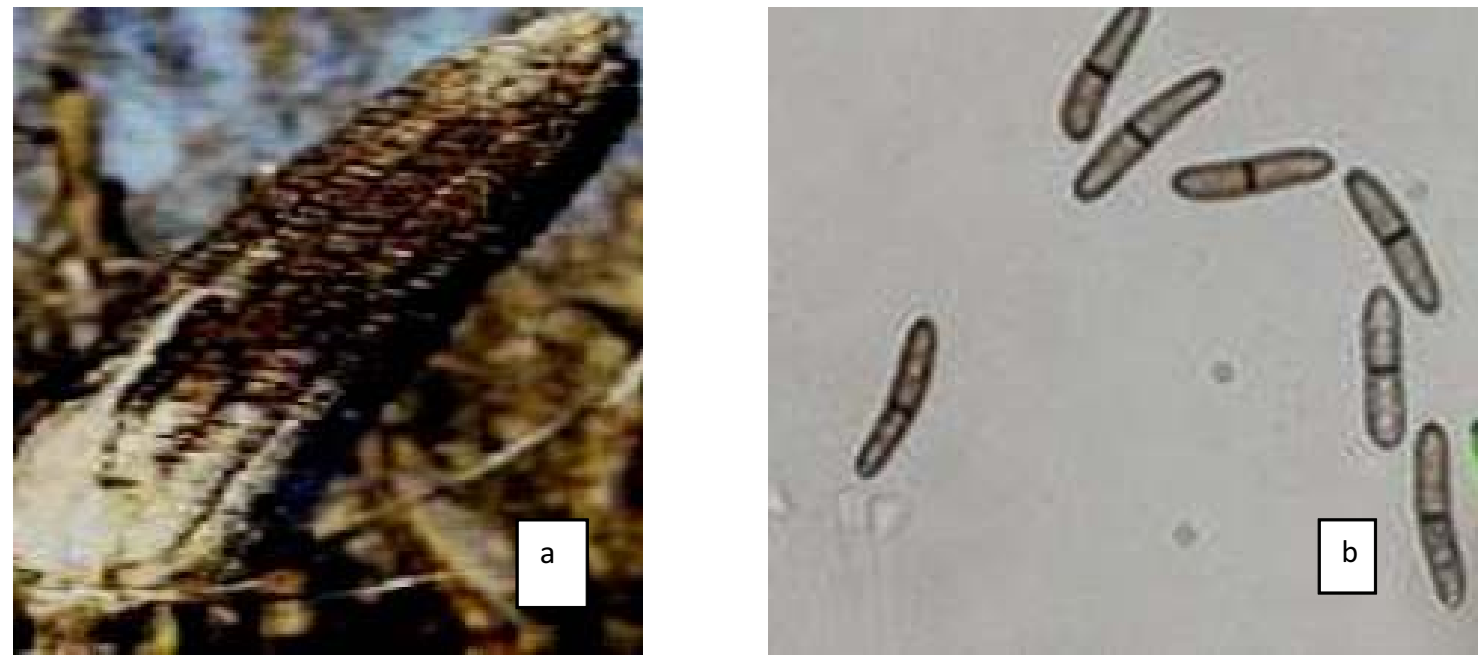

Gambar 2. Tongkol jagung yang terinfeksi Diplodia (a) dan Konidia Diplodia (b)

Hasil pengujian ketahanan di lapangan pada penyakit busuk tongkol yang disebabkan oleh cendawan Gibberella ear rot

Penyakit ini banyak menyerang pada tongkol dan biji jagung, tetapi cendawan ini juga bisa menyerang pada bagian lain misalnya pada batang atau pelepah. Hasil pengamatan setelah panen jagung di Limang Kabupaten tanah karo Sumatera Utara menunjukkan bahwa dari 25 Hybrid jagung yang diuji termasuk 2 hybrid sebagai cek tahan dan cek rentan ternyata ada 7 Hybrid jagung hibrida yang tahan terhadap penyakit busuk tongkol Kenia 2, NK33, Bima 3, Bima 10, Bima 12 Q, NEl-9008 dan cek tahan sedangkan yang bersifat agak tahan ada 9 hybrid yaitu KENIA-3, DK979, NK22 dan P12, Gumarang, Srikandi Putih, Lamuru dan Sukmaraga sedangkan 9 hybrid yang lain bersifat rentan dan sangat rentan termasuk X7B457(Tabel 2). Hal ini menunjukkan bahwa ketahanan suatu varietas sangat diutamakan dibanding dengan pengendalian yang lain dan menurut Cullen et al., 1983 yang mengatakan bahwa ketahanan varietas tergantung dari faktor genotipnya, sehingga dalam penentuan varietas yang tahan diperlukan genotipgenotip yang unggul dan tahan terhadap cendawan Gibberella sebelum dilakukan penyilangan.

Tabel2. Rata-rata intensitas serangan penyakit Gibberella pada uji ketahanan 25 Hybrid jagung di Limang kabupaten Karo Sumatera utara.

\begin{tabular}{llcc}
\hline No & CODE HYBRID & Intensitas serangan $(\%)$ & Kriteria serangan \\
\hline 1 & KENIA-3 & 29,89 & AT \\
2 & KENIA-2 & 17,03 & $\mathrm{~T}$ \\
3 & P23 & 50,40 & $\mathrm{R}$ \\
4 & P21 & 50,11 & $\mathrm{R}$ \\
5 & DK979 & 30,56 & AT \\
6 & NK22 & 24,52 & AT \\
7 & NK33 & 19,0 & T \\
8 & P29 & 37,53 & AT \\
\hline
\end{tabular}




\begin{tabular}{llcc}
\hline No & \multicolumn{1}{c}{ CODE HYBRID } & Intensitas serangan (\%) & Kriteria serangan \\
\hline 9 & PERTIWI & 65,19 & $\mathrm{SR}$ \\
10 & BISI 816 & 47,07 & $\mathrm{R}$ \\
11 & BISI 2 & 42,69 & $\mathrm{R}$ \\
12 & P12 & 35,13 & $\mathrm{AT}$ \\
13 & BIMA 3 & 19,25 & $\mathrm{~T}$ \\
14 & BIMA 10 & 15,90 & $\mathrm{~T}$ \\
15 & BIMA 12Q & 18,58 & $\mathrm{~T}$ \\
16 & PULUT LOKAL & 42,45 & $\mathrm{R}$ \\
17 & SRIKANDI PUTIH & 40,75 & $\mathrm{R}$ \\
18 & ANOMAN & 62,09 & $\mathrm{SR}$ \\
19 & GUMARANG & 39,27 & $\mathrm{AT}$ \\
20 & NEI- 9008 & 18,13 & $\mathrm{~T}$ \\
21 & SRIKANDI PUTIH & 36,25 & AT \\
22 & Lamuru & 27,18 & AT \\
23 & SUKMARAGA & 25,49 & AT \\
24 & X8B649 (Cek Tahan) & 19,76 & $\mathrm{~T}$ \\
25 & X7B457 (Cek Rentan) & 72,50 & $\mathrm{SR}$ \\
\hline
\end{tabular}

Keterangan: $\mathrm{ST}=$ Sangat Tahan, $\mathrm{T}=$ Tahan, $\mathrm{AT}=$ Agak Tahan, $\mathrm{R}=$ Rentan, $\mathrm{SR}=$ Sangat Rentan

Hal ini karena waktu tidak ada pertanaman, cendawan dapat bertahan pada sisa-sisa tanaman yang terinfeksi dalam fase hifa atau piknidia dan peritesia yang berisi spora. Pada lingkungan yang sesuai untuk perkembangannya, spora akan keluar dari piknidia atau peritesia, kemudian spora dipermukaan tanaman jagung akan tumbuh dan menginfeksi melalui akar atau pangkal batang, infeksi awal dapat melalui luka atau membentuk sejenis apresoria yang mampu berpenetrasi ke jaringan tanaman. Spora/konidia yang terbawa angin dapat menginfeksi ke tongkol dan biji yang terinfeksi bila ditanam dapat menyebabkan penyakit busuk tongkol (Shurtleff 1980). Penyakit busuk tongkol Gibberella juga lebih cepat menyebar apabila biji terserang penggerek tongkol, dibanding pada tongkol jagung yang tidak terserang atau sehat (Lipps dan Mills, 2005)
Penyakit busuk tongkol yang disebabkan oleh cendawan Diplodia ear rot

Kerugian busuk tongkol Diplodia dapat mengurangi potensial hasil, hal ini apabila terjadi sebelum masa pemasakan biji, tanaman mengalami kematian akibat infeksi, biji-biji yang dihasilkan tidak normal karena terhentinya proses pengisian biji sehingga menghasilkan ukuran kernel dan bobot biji lebih kecil. Kualitas biji berpengaruh karena perkembangan diplodia sangat cepat dibanding dengan penyakit Giberella sehingga apabila terinfeksi menyebabkan biji mengalami pembusukan (Lamprecht et al., 2011)

Hasil pengamatan setelah panen jagung di Limang Kabupaten tanah karo Sumatera Utara menunjukkan bahwa dari 25 Hybrid jagung yang diuji termasuk 2 hybrid sebagai cek tahan dan cek rentan ternyata ada 6 Hybrid jagung hibrida yang tahan terhadap penyakit busuk tongkol Diplodia 
yaitu Kenia 3, NK33, Bima 3, Bima 12 Q, NEI-9008 dan X8B649 (cek tahan) sedangkan yang bersifat agak tahan ada 11 hybrid yaitu P21, DK979, NK22, P29, Bisi 2, P12, Bima 10, Gumarang, Srikandi Putih, Lamuru dan Sukmaraga sedangkan 8 hybrid yang lain bersifat rentan dan sangat rentan termasuk X7B457 atau cek rentan (Tabel 3). Penyakit Diplodia menurut Lamprecht et al., 2011, selain pengendaliannya menggunakan varietas tahan, penyakit ini juga dapat dikendalikan dengan fungisida yang mempunyai bahan aktif kelompok benzimidazole fungisida seperti benomyl. Beberapa isolat dari Diplodia maydis dapat menyebabkan vivipary perkecambahan dini pada bagian biji, sedangkan Diplodia dari species lain misalnya natalensis adalah patogen yang dapat menyebabkan busuk pada beberapa tanaman termasuk ubi, pisang, dan jeruk manis.

Tabel 3. Rata-rata intensitas serangan penyakit Diplodia pada uji ketahanan 25 Hybrid jagung di Limang kabupaten Karo Sumatera utara.

\begin{tabular}{|c|c|c|c|}
\hline No & CODE HYBRID & Intensitas serangan (\%) & Kriteria serangan \\
\hline 1 & KENIA-3 & 35,20 & AT \\
\hline 2 & KENIA-2 & 19,72 & $\mathrm{~T}$ \\
\hline 3 & P23 & 59,50 & $\mathrm{R}$ \\
\hline 4 & P21 & 54,75 & $\mathrm{R}$ \\
\hline 5 & DK979 & 34,28 & AT \\
\hline 6 & NK22 & 28,74 & AT \\
\hline 7 & NK33 & 18,42 & $\mathrm{~T}$ \\
\hline 8 & P29 & 35,69 & AT \\
\hline 9 & PERTIWI & 61,29 & SR \\
\hline 10 & BISI 816 & 52,40 & $\mathrm{R}$ \\
\hline 11 & BISI 2 & 30,17 & AT \\
\hline 12 & P12 & 39,10 & AT \\
\hline 13 & BIMA 3 & 17,45 & $\mathrm{~T}$ \\
\hline 14 & BIMA 10 & 29,20 & AT \\
\hline 15 & BIMA $12 Q$ & 18,60 & $\mathrm{~T}$ \\
\hline 16 & PULUT LOKAL & 50,09 & $\mathrm{R}$ \\
\hline 17 & SRIKANDI PUTIH & 47,29 & $\mathrm{R}$ \\
\hline 18 & ANOMAN & 70,43 & $\mathrm{R}$ \\
\hline 19 & GUMARANG & 28,75 & AT \\
\hline 20 & NEI- 9008 & 19,25 & $\mathrm{~T}$ \\
\hline 21 & SRIKANDI PUTIH & 39,40 & AT \\
\hline 22 & Lamuru & 32,67 & AT \\
\hline 23 & SUKMARAGA & 29,42 & AT \\
\hline 24 & X8B649 (Cek Tahan) & 17,25 & $\mathrm{~T}$ \\
\hline 25 & X7B457 (Cek Rentan) & 64,50 & SR \\
\hline
\end{tabular}

Keterangan : $\mathrm{ST}=$ Sangat Tahan, $\mathrm{T}=$ Tahan, $\mathrm{AT}=$ Agak Tahan, $\mathrm{R}=$ Rentan, $\mathrm{SR}=$ Sangat Rentan 


\section{Simpulan}

Pada 25 hybrid jagung yang diuji terhadap penyakit busuk tongkol Gibberella ada 7 Hybrid jagung hibrida yang tahan terhadap penyakit busuk tongkol Kenia-2, NK33, Bima 3, Bima 10, Bima 12 Q, NEI9008 dan cek tahan sedangkan yang bersifat agak tahan ada 9 hybrid yaitu Kenia-3, DK979, NK22 dan P12, Gumarang, Srikandi Putih, Lamuru dan Sukmaraga sedangkan 9 hybrid yang lain bersifat rentan dan sangat rentan. 25 Hybrid jagung yang diuji terhadap penyakit busuk tongkol Diplodia ada 6 Hybrid jagung hibrida yang tahan terhadap penyakit busuk tongkol Kenia-2, NK33, Bima 3, Bima 12 Q, NEl-9008 dan X8B649 sedangkan yang bersifat agak tahan ada 11 hybrid yaitu Kenia-3, DK979, NK22, P29, Bisi 2, P12, Bima 10, Gumarang, Srikandi Putih, Lamuru dan Sukmaraga sedangkan 8 hybrid yang lain bersifat rentan dan sangat rentan.

\section{Ucapan Terima Kasih}

Ucapan terima kasih disampaikan kepada Bapak Terkelin Sembiring sebagai ketua kelompok tani yang telah banyak membantu dalam penelitian di Lapangan

\section{Daftar Pustaka}

Akinsanmi, O.A., Mitter, V., Simfendorfer, S., Backhouse, D., Chakraborty,S. 2004. Identity and Pathogenicity of Fusarium spp. isolate frm wheat fields in Queensland and Northern

New South Wales Australian Journal of Agricultural Research - AUST J AGR RES, VOL 55, no. 1, 2004.

Beyer M, and Verreet J-A . 2005. Germination of Gibberella zeae ascospores as affected by age of spores after discharge and environmental factors. European Journal of Plant Pathology 111: 381389
Charles, W.K. 2009. Disease of Corn Diplodia Ear Rot. http://www. Agricultural.purdue.edu (Diakses : 22 April 2015)

CIMMYT. 2004. Maize Diseases: A guide for Field Identification. 4th Edition. Mexico, D.F.: CIMMYT

Cullen, D., R.W. Caldwell and E.B. Smalley. 1983. Susceptibility of maize to Gibberella zeae ear rot: relationship to host genotype, pathogen virulence, and zearalenone contamination. Plant Disease 67:8991.

Kogan, M . 1974. Plant resistance in pest management, p. 103-143. In Metcalf, R.L. \& W. H. Lukman (eds). Introduction to pest management. John Willey \& Sons. N.Y.

Lamprecht, S.C., Crous, P.W., Groenewald, J.Z., Tewoldemedhin, Y.T., Marasas, W.F.O., 2011. Diplonine, a neurotoxin isolated from cultures of the fungus Stenocarpella maydis (Berk.) Sacc. that induces diplodiosis. J. Agri. Food Chem. 59, 9039-9044.

Lipps, P.E., A.E. Dorrance and D.R. Mills. 2005. Gibberella stalk rot of corn. Factsheet Extension. Ohio State University Extension. http://ohioline. osu.edu/ac-fact/0033.html (Diakses : 29 April 2015)

Mitter, V., Francl, L.J. and Simpfendorfer, S. 2006. Ascosporic and conidial inoculum of Gibberella zeae play different roles in Fusarium head blight and crown rot of wheat in Australia and the USA. Australian plant pathology Juli 2006, Volume 35 , Issue 4 pp 441-452

Shurtleff, M.C. 1980. Compendium of Corn Diseases. Second Edition. The American Phytopa-thological Society, USA, $105 p$. 